\title{
Analisa User Experience pada TFME Interactive Learning Media Menggunakan User Experience Questionnaire
}

\author{
Sandi Prasetyaningsih ${ }^{1}$, Widya Putri Ramadhani ${ }^{2}$ \\ ${ }^{1,2}$ Politeknik Negeri Batam \\ Multimedia and Networking Engineering Program \\ Jln. Ahmad Yani, Batam Centre, Batam 29461, Indonesia \\ E-mail: sandi@polibatam.ac.id, widyap402@gmail.com
}

\begin{abstract}
Abstrak
Multimedia interaktif merupakan media pembelajaran yang memanfaatkan teknologi untuk memudahkan proses pembelajaran. Beberapa sekolah maupun lembaga pendidikan mulai menggunakannya sebagai media pembelajaran, salah satunya Teaching Factory Manufacturing of Electronics (TFME) Politeknik Negeri Batam menggunakan TFME Interactive Learning Media sebagai media pembelajaran interaktif. Tujuan penelitian ini adalah membuat media pembelajaran interaktif berbasis website dan mengetahui kualitas pengalaman pengguna terhadap TFME Interactive Learning Media. Implementasi produk menggunakan model perancangan ADDIE dengan lima tahapan yaitu analysis, design, development, implementation, dan evaluation. Penelitian ini menggunakan metode penelitian kuantitatif berdasarkan user experience questionnaire (UEQ) yang mempunyai enam skala utama yaitu novelty, perspicuity, dependability, efficiency, attractiveness, dan stimulation. Hasil penelitian menunjukkan bahwa produk tersebut dapat menjadi media pembalajaran interaktif bagi mahasiswa dan semua aspek UEQ memiliki nilai rata-rata $>0.8$ yaitu novelty (1.03), perspicuity (1.09), dependability (1.18), efficiency (1.15), attractiveness (1.23), dan stimulation (1.20).
\end{abstract}

Kata kunci: User Experience, Interactive Learning, User Experience Questionnaire

\begin{abstract}
One of the cutting-edge technologies implementations can be seen on interactive multimedia that usually use in learning systems. School and informal education institutions start to use this system as their main media to deliver courses. For instance, Teaching Factory Manufacturing of Electronics (TFME) in Politeknik Negeri Batam. This study aims to generate interactive media that run on websites and to observe the experience value while using interactive media of TFME. ADDIE is utilized as a design method of system. ADDIE stands for analysis, design, development, implementation, and evaluation. Furthermore, during the research, qualitative method is used to analyze user experience questionnaire (UEQ) which has six scales, namely novelty, perspicuity, dependability, efficiency, attractiveness, and stimulation. The result of study shows that product can be employed as interactive multimedia for students well as UEQ's scale has average $>0.8$. It can be detailed in novelty (1.03), perspicuity (1.09), dependability (1.18), efficiency (1.15), attractiveness (1.23), and stimulation (1.20).
\end{abstract}

Keywords: User Experience, Interactive Learning, User Experience Questionnaire

\section{Introduction}

Pada zaman globalisasi ini, perkembangan teknologi semakin cepat sehingga dunia pendidikan harus meningkatkan mutu pendidikan agar selalu sesuai dengan perkembangan teknologi, khususnya dalam kegiatan belajar mengajar [1]. Dari yang awalnya menggunakan papan tulis dan kapur sebagai media pembelajaran dan sekarang menggunakan multimedia interaktif sebagai media pembelajaran.

Multimedia interaktif merupakan sebuah media pembelajaran yang memanfaatkan teknologi untuk mempermudah proses pembelajaran [2]. Beberapa sekolah maupun lembaga pendidikan mulai menggunakan multimedia interaktif sebagai media pembelajaran, termasuk salah satunya Teaching Factory Manufacturing of Electronics (TFME) Polibatam.

TFME Polibatam merupakan sebuah laboratorium yang ada di Polibatam yang berfokus pada bidang elektronik mikro untuk menghasilkan produk-produk seperti IC packaging, $P C B$ manufacturing dan $P C B$ 
assembly [3]. Laboratorium TFME menyediakan pelatihan yang relevan untuk meningkatkan pengetahuan, keterampilan praktis dan kompetensi kepada para mahasiswa dari jurusan elektronika [4].

Salah satu pemanfaatan multimedia interaktif yang dilakukan oleh Teaching Factory Manufacturing of Electronics (TFME) Polibatam adalah memanfaatkan jenis multimedia interaktif berbasis website sebagai media pembelajaran untuk para mahasiswa dari Program Studi Teknik Elektronika dan Teknik Elektronika Manufaktur.

TFME Interactive Learning Media adalah suatu produk multimedia interaktif yang berbasis website, dimana didalam website tersebut terdapat materi-materi terkait penjelasan mengenai Teaching Factory Manufacturing of Electronics (TFME), IC packaging, PCB manufacturing, dan PCB assembly. Produk tersebut dibuat agar memudahkan para mahasiswa dalam memahami proses prosedur pada setiap mesin yang ada di IC packaging, PCB manufacturing, dan PCB assembly [4].

Suatu produk dikatakan berhasil jika dapat memenuhi kebutuhan pengguna yang akan menimbulkan kepuasan saat menggunakan produk tersebut [5]. Agar produk yang dihasilkan sesuai dengan standard, maka diperlukan evaluasi untuk menilai kualitas suatu produk. Salah satu evaluasi yang diperlukan adalah evaluasi terkait user experience. User experience merupakan pengalaman pengguna terhadap suatu produk atau teknologi saat mereka menggunakannya [6].

Untuk menganalisa kualitas user experience, metode penelitian yang dipakai adalah user experience questionnaire (UEQ). Metode ini dapat membantu penilaian kualitas pengalaman pengguna secara subjektif yang mudah untuk dipraktikan, terpercaya, dan valid. Metode UEQ merupakan salah satu metode perhitungan cepat dari pengalaman pengguna terhadap produk interaktir [7]. Selain itu, UEQ digunakan untuk tujuan membandingkan level user experience antara dua produk, menguji user experience suatu produk, dan menentukan area perbaikan [8]. Metode user experience questionnaire mempunyai enam skala utama yaitu kebaruan (novelty), kejelasan (perspicuity), ketepatan (dependability), efisiensi (efficiency), daya tarik (attractiveness), dan stimulasi (stimulation) [5].

Berdasarkan latar belakang tersebut, penulis membuat suatu penelitian yaitu "Analisa User Experience Pada TFME Interactive Learning Media Menggunakan User Experience Questionnaire".

Adapun yang menjadi tujuan penelitian ini adalah membuat TFME Interactive Learning Media sebagai media pembelajaran interaktif dan mengetahui kualitas pengalaman pengguna ketika menggunakan TFME Interactive Learning Media sebagai media pembelajaran. Penelitian ini diharapkan bermanfaat untuk sebagai media pembelajaran bagi mahasiswa dari Program Studi Teknik Elektronika dan Teknik Elektronika Manufaktur serta dapat menjadi bahan referensi dan kajian mengenai analisa user experience menggunakan user experience questionnaire.

\section{Landasan Teori}

\subsection{Tinjauan Pustaka}

Terdapat beberapa penelitian tentang analisa user experience yang menggunakan user experience questionnaire. Penelitian pertama [9] yang berjudul Analisis Aplikasi Mobile Transportasi Online Menggunakan User Experience Questionnaire pada Era Milenial dan $Z$ yang membahas tentang user experience mahasiswa pada era milenial dan $\mathrm{Z}$ terhadap aplikasi mobile transportasi. Hasil dari penelitian tersebut adalah semua kategori utama UEQ mendapatkan nilai di area positif.

Penelitian kedua [10] yang berjudul Evaluasi User Experience Produk iDigital Museum dengan Menggunakan UEQ yang membahas tentang user experience pengunjung Museum Geologi ketika memakai Aplikasi Interaktif dengan tema Bandung Purba. Hasil dari penelitian tersebut adalah 6 skala utama UEQ menunjukan impresi positif.

Penelitian ketiga [5] yang berjudul Analisis Pengalaman Pengguna pada Website E-Commerce Dengan Menggunakan Usability Testing dan User Experience Questionnaire (UEQ) (Studi pada Lazada.co.id, Blibli.com dan JD.id) yang membahas tentang perbandingan antara website JD.id, Lazada.co.id, dan Blibli.com dalam aspek kegunaan dan pengalaman pengguna terhadap website tersebut. Hasil dari penelitian tersebut adalah website Blibli.com lebih unggul dari kedua website tersebut.

Kemudian penelitian keempat [11] yang berjudul Analisis Aspek Usability dan User Experience Website dan Aplikasi Mobile Radio Streaming (Studi pada Website dan Aplikasi Mobile Radio Prambors) yang membahas tentang aspek pengalaman pengguna dan kegunaan terhadap aplikasi dan website Radio Prambors. Hasil dari penelitian tersebut menunjukan bahwa setiap kategori UEQ rata-rata mencapai $\geqslant 0.8$.

Tabel 1 memperlihatkan perbandingan beberapa jurnal yang menggunakan user experience questionnaire (UEQ) sebagai metode penelitian untuk mengukur kualitas user experience terhadap suatu produk.

TABLE I

TINJAUAN PUSTAKA

\begin{tabular}{|c|l|l|l|l|}
\hline No & \multicolumn{1}{|c|}{$\begin{array}{c}\text { Judul } \\
\text { Penelitian }\end{array}$} & Metode & Hasil & Data \\
\hline 1. & $\begin{array}{l}\text { Analisis } \\
\text { Aplikasi }\end{array}$ & UEQ & $\begin{array}{l}\text { Semua } \\
\text { kategori }\end{array}$ & $\begin{array}{l}\text { Jurnal Sistem } \\
\text { Informasi }\end{array}$ \\
\hline
\end{tabular}




\begin{tabular}{|c|c|c|c|c|}
\hline & $\begin{array}{l}\text { Mobile } \\
\text { Transportasi } \\
\text { Online } \\
\text { Menggunakan } \\
\text { User } \\
\text { Experience } \\
\text { Questionnaire } \\
\text { pada Era } \\
\text { Milenial dan Z }\end{array}$ & & $\begin{array}{l}\text { utama } \\
\text { UEQ } \\
\text { mendapat } \\
\text { kan nilai } \\
\text { di area } \\
\text { positif }\end{array}$ & $\begin{array}{l}\text { Bisnis 02(2019) } \\
\text { oleh Leon } \\
\text { Andretti } \\
\text { Abdillah }\end{array}$ \\
\hline 2. & $\begin{array}{l}\text { Evaluasi User } \\
\text { Experience } \\
\text { Produk } \\
\text { iDigital } \\
\text { Museum } \\
\text { dengan } \\
\text { Menggunakan } \\
\text { UEQ }\end{array}$ & UEQ & $\begin{array}{l}6 \text { skala } \\
\text { utama } \\
\text { UEQ } \\
\text { menunjuk } \\
\text { an impresi } \\
\text { positif }\end{array}$ & $\begin{array}{l}\text { Jurnal } \\
\text { Teknologi } \\
\text { Informasi Vol. } \\
\text { 2, No.2 oleh } \\
\text { Anang Sularsa, } \\
\text { Eko Nugroho, } \\
\text { dan Ary Setijadi } \\
\text { Prihatmanto }\end{array}$ \\
\hline 3. & $\begin{array}{l}\text { Analisis } \\
\text { Pengalaman } \\
\text { Pengguna } \\
\text { pada Website } \\
\text { E-Commerce } \\
\text { Dengan } \\
\text { Menggunakan } \\
\text { Usability } \\
\text { Testing dan } \\
\text { User } \\
\text { Experience } \\
\text { Questionnaire } \\
\text { (UEQ) (Studi } \\
\text { pada } \\
\text { Lazada.co.id, } \\
\text { Blibli.com dan } \\
\text { JD.id) }\end{array}$ & UEQ & $\begin{array}{l}\text { Website } \\
\text { Blibli.co } \\
\text { m lebih } \\
\text { unggul } \\
\text { dari kedua } \\
\text { website } \\
\text { tersebut }\end{array}$ & $\begin{array}{l}\text { Jurnal } \\
\text { Pengembangan } \\
\text { Teknologi } \\
\text { Informasi dan } \\
\text { Ilmu Komputer } \\
\text { Vol. 2, No. 11, } \\
\text { November } \\
\text { 2018, hlm. } \\
\text { 5862-5870 oleh } \\
\text { Ahmad Luthfi } \\
\text { Teguh } \\
\text { Adinegoro, } \\
\text { Retno Indah } \\
\text { Rokhmawati, } \\
\text { dan Hanifah } \\
\text { Muslimah } \\
\text { Az-Zahra. }\end{array}$ \\
\hline 4. & $\begin{array}{l}\text { Analisis } \\
\text { Aspek } \\
\text { Usability dan } \\
\text { User } \\
\text { Experience } \\
\text { Website dan } \\
\text { Aplikasi } \\
\text { Mobile Radio } \\
\text { Streaming } \\
\text { (Studi pada } \\
\text { Website dan } \\
\text { Aplikasi } \\
\text { Mobile Radio } \\
\text { Prambors)" }\end{array}$ & UEQ & $\begin{array}{l}\text { Setiap } \\
\text { kategori } \\
\text { UEQ } \\
\text { rata-rata } \\
\text { mencapai } \\
\geq 0.8\end{array}$ & $\begin{array}{l}\text { Jurnal } \\
\text { Pengembangan } \\
\text { Teknologi } \\
\text { Informasi dan } \\
\text { Ilmu Komputer } \\
\text { Vol. 2, No.12, } \\
\text { Desember 2018, } \\
\text { hlm. 6391-6400 } \\
\text { oleh } \\
\text { Muhammad } \\
\text { Audi, Retno } \\
\text { Indah } \\
\text { Rokhmawati, } \\
\text { Hanifah } \\
\text { Muslimah } \\
\text { Az-Zahra. }\end{array}$ \\
\hline
\end{tabular}

\subsection{Multimedia Interaktif}

Multimedia interaktif berarti sebuah media yang membuat dan menggabungkan beberapa unsur media seperti suara, animasi, grafis, teks, dan video dengan memanfaatkan komputer yang disajikan secara interaktif, dimana pengguna dapat berinteraksi secara aktif dengan media tersebut [12].

Multimedia interaktif merupakan sebuah teknologi yang membuat sebuah pembelajaran menjadi lebih interaktif, menarik dan pengguna bisa belajar kapan dan dimana saja tanpa harus berada dilingkungan sekolah [13].

\subsection{Website}

Website merupakan sebuah halaman web yang berisi tentang informasi dalam bentuk animasi, text, video, audio, dan gambar yang disajikan melalui jaringan internet [14].

Website merupakan salah satu layanan untuk menyampaikan informasi kepada pengguna yang menggunakan perangkat komputer dan terhubung ke internet. Website sendiri mempunyai dua sifat yaitu, dinamis dan statis. Sebuah website yang mana informasi yang diberikan tetap dan tidak berubah berarti website tersebut bersifat statis, sedangkan website yang mana informasi yang diberikan berubah berarti website tersebut bersifat dinamis [15].

\subsection{Teaching Factory Manufacturing of Electronics (TFME)}

Teaching Factory Manufacturing of Electronics (TFME) Polibatam merupakan sebuah laboratorium yang ada di Polibatam dan fokus pada bidang Elektronik Mikro yang menghasilkan produk-produk seperti IC packaging, PCB manufacturing dan $P C B$ assembly [3].

Laboratorium TFME menyediakan pelatihan yang relevan untuk meningkatkan pengetahuan, keterampilan praktis dan kompetensi kepada para mahasiswa dari jurusan elektronika [4].

\subsection{TFME Interactive Learning Media}

TFME Interactive Learning Media adalah suatu produk multimedia interaktif yang berbasis website, dimana di dalam website tersebut terdapat materi-materi terkait penjelasan mengenai Teaching Factory Manufacturing of Electronics (TFME), IC packaging, $P C B$ manufacturing, dan $P C B$ assembly. Produk tersebut dibuat agar memudahkan para mahasiswa dalam memahami proses prosedur pada setiap mesin yang ada di IC packaging, $P C B$ manufacturing, dan PCB assembly [4].

\subsection{User Experience}

User experience atau yang biasa disingkat menjadi UX merupakan pengalaman pengguna terhadap suatu produk atau teknologi saat mereka menggunakannya [6].

User experience dari suatu produk dapat dikatakan baik jika mempunyai aspek psikologis dan perilaku pengguna saat menggunakan produk. Agar produk yang dihasilkan mempunyai user experience yang baik, maka porduk tersebut harus mempunyai kesesuaian antara kebutuhan pengguna dengan fitur yang ada di produk [16]. 


\subsection{User Experience Questionnaire (UEQ)}

Metode yang dapat membantu penilaian kualitas pengalaman pengguna secara subjektif yang mudah untuk dipraktikan, terpercaya, dan valid adalah user experience questionnaire [5].

Format kuesioner user experience questionnaire (UEQ) mendukung pengguna untuk mengungkapkan sikap, perasaan, dan kesan yang muncul ketika menggunakan sebuah produk secara cepat [10]. User experience questionnaire mempunyai 26 pertanyaan dari enam skala utama yaitu:

a. Kebaruan (Novelty)

Aspek kebaruan merupakan penilaian pengguna terhadap produk, apakah produk tersebut kreatif atau tidak serta seberapa inovatif desain suatu produk. Aspek kebaruan mempunyai empat indikator, yaitu:

1) Conservative/Innovative,

2) Creative/Dull,

3) Usual/Leading edge, dan

4) Inventive/Conventional.

b. Kejelasan (Perspicuity)

Aspek kejelasan merupakan penilaian pengguna terhadap produk, apakah produk tersebut dapat dipelajari oleh pengguna atau tidak serta apakah pengguna dapat membiasakan diri dengan produk. Aspek kejelasan mempunyai empat indikator, yaitu:

1) Easy to learn/Difficult to learn,

2) Clear/Confusing,

3) Complicated/Easy, dan

4) Understandable/Not understandable.

c. Ketepatan (Dependability)

Aspek ketepatan merupakan penilaian pengguna terhadap produk, apakah produk tersebut aman atau tidak saat digunakan serta seberapa besar ketepatan yang dirasakan oleh pengguna melalui kontrol yang pengguna miliki. Aspek ketepatan mempunyai empat indikator, yaitu:

1) Meets expectations/Does not meet expectations,

2) Obstructive/Supportive,

3) Unpredictable/Predictable, dan

4) Secure/Not secure.

d. Efisiensi (Efficiency)
Aspek efisiensi merupakan penilaian pengguna terhadap produk, apakah produk tersebut cepat dan efisien ketika digunakan serta seberapa besar pengguna dapat menyelesaikan tugasnya tanpa usaha yang besar atau efisien. Aspek efisien mempunyai empat indikator, yaitu:

1) Inefficient/Efficient,

2) Organized/Cluttered,

3) Fast/slow, dan

4) Impractical/Practical.

e. Daya tarik (Attractiveness)

Aspek daya tarik merupakan penilaian pengguna terhadap produk, apakah pengguna suka atau tidak suka terhadap produk tersebut serta seberapa besar pengguna menyukai tampilan pada produk. Aspek daya tarik mempunyai enam indikator, yaitu:

1) Unpleasant/Pleasant,

2) Unlikable/Pleasing,

3) Good/Bad,

4) Annoying/Enjoyable,

5) Friendly/Unfriendly, dan

6) Attractive/Unattractive.

f. Stimulasi (Stimulation)

Aspek stimulasi merupakan penilaian pengguna terhadap produk, apakah produk tersebut membosankan atau menarik serta seberapa termotivasi pengguna saat menggunakan produk. Aspek stimulasi mempunyai empat indikator, yaitu:

1) Motivating/Demovating,

2) Valuable/Inferior,

3) Boring/Exiting, dan

4) Not interesting/Interesting.

\subsection{UEQ Data Analysis Tool}

Merupakan tool khusus yang dapat digunakan untuk menganalisis hasil kuesioner UEQ. UEQ Data Analysis Tool berupa file excel yang dapat diunduh dari situs website resmi UEQ. Untuk menggunakannya, kita hanya perlu memasukkan data dari responden ke dalam tab "data" [17].

Kita dapat menggunakan UEQ data analysis tool untuk memproses data kuesioner UEQ. Untuk mengetahui arti dari nilai yang dihasilkan oleh masing-masing skala UEQ dapat dilakukan dengan cara membandingkan nilai yang dihitung dari setiap 
skala dengan nilai yang dapat dilihat pada tabel 2 [18].

TABLE 2

BENCHMARK INTERVAL UNTUK SKALA UEQ

\begin{tabular}{|c|c|c|c|c|c|c|}
\hline & $\begin{array}{l}\text { Daya } \\
\text { Tarik }\end{array}$ & Kejelasan & Efisiensi & Ketepatan & Stimulasi & Kebaruan \\
\hline $\begin{array}{l}\text { Excell } \\
\text { ent }\end{array}$ & $\geq 1.75$ & $\geq 1.9$ & $\geq 1.78$ & $\geq 1.65$ & $\geq 1.55$ & $\geq 1.4$ \\
\hline Good & $\begin{array}{l}\geq 1.52 \\
<1.75\end{array}$ & $\begin{array}{l}\geq 1.56 \\
<1.9\end{array}$ & $\begin{array}{l}\geq 1.47 \\
<1.78\end{array}$ & $\begin{array}{l}\geq 1.48 \\
<1.65\end{array}$ & $\begin{array}{l}\geq 1.31 \\
<1.55\end{array}$ & $\begin{array}{l}\geq 1.05 \\
<1.4\end{array}$ \\
\hline $\begin{array}{l}\text { Above } \\
\text { Avera } \\
\text { ge }\end{array}$ & $\begin{array}{l}\geq 1.17 \\
<1.52\end{array}$ & $\begin{array}{l}\geq 1.08 \\
<1.56\end{array}$ & $\begin{array}{l}\geq 0.98 \\
<1.47\end{array}$ & $\begin{array}{l}\geq 1.14 \\
<1.48\end{array}$ & $\begin{array}{l}\geq 0.99 \\
<1.31\end{array}$ & $\begin{array}{l}\geq 0.71 \\
<1.05\end{array}$ \\
\hline $\begin{array}{l}\text { Below } \\
\text { Avera } \\
\text { ge }\end{array}$ & $\begin{array}{l}\geq 0.7 \\
<1.17\end{array}$ & $\begin{array}{l}\geq 0.64 \\
<1.08\end{array}$ & $\begin{array}{l}\geq 0.54 \\
<0.98\end{array}$ & $\begin{array}{l}\geq 0.78 \\
<1.14\end{array}$ & $\begin{array}{l}\geq 0.5 \\
<0.99\end{array}$ & $\begin{array}{l}\geq 0.3 \\
<0.71\end{array}$ \\
\hline $\mathrm{Bad}$ & $<0.7$ & $<0.64$ & $<0.54$ & $<0.78$ & $<0.5$ & $<0.3$ \\
\hline
\end{tabular}

\subsection{Model ADDIE}

Analysis, design, development, implementation, dan evaluation. merupakan kepanjangan dari ADDIE. Model ADDIE merupakan model untuk desain pembelajaran yang sifatnya lebih umum. Salah satu fungsi ADDIE adalah memandu produksi yang dinamis, efektif dan mendukung struktur dasar dari pelatihan itu sendiri [18].

Model ADDIE merupakan model yang menunjukkan langkah yang cermat dan jelas untuk membuat produk serta model ini dirancang khusus untuk pembelajaran multimedia [13]. Model ADDIE mempunyai lima tahapan yaitu:
a. Analysis (analisis)
b. Design (perancangan)
c. Development (pengembangan)
d. Implementation (implementasi)
e. Evaluation (evaluasi)

Gambar 1. adalah gambar dari tahapan ADDIE.

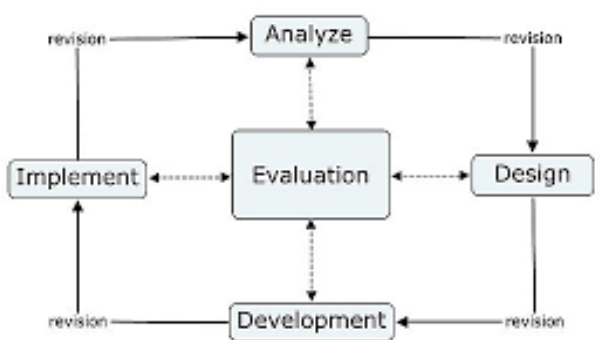

Gambar 1: Tahapan ADDIE

\subsection{Simple Random Sampling}

Teknik pengambilan sampel setiap anggota populasi dimana setiap anggotanya mempunyai kesempatan yang sama untuk dipilih sebagai sampel [20].

Teknik pengambilan sampel dari suatu populasi yang seragam, yang dilakukan secara acak terlepas dari tingkat populasinya [21].

\section{Analisa dan Perancangan}

\subsection{Perancangan}

Pada tahapan perancangan akan dilakukan proses pembuatan produk TFME Interactive Learning Media berdasarkan model perancangan ADDIE. Model ADDIE sendiri mempunyai lima tahapan yaitu:

a. Analysis (analisis)

Dalam tahapan analisis dilakukan analisa kebutuhan perangkat dan materi-materi yang dibutuhkan dalam TFME Interactive Learning Media seperti video, gambar, dan dokumen. Perangkat yang digunakan yaitu Adobe Animate CC 2018. Evaluasi yang dilakukan pada tahapan analisis yang dapat dilihat pada tabel 3 .

TABLE 3

EVALUASI TAHAP ANALISI

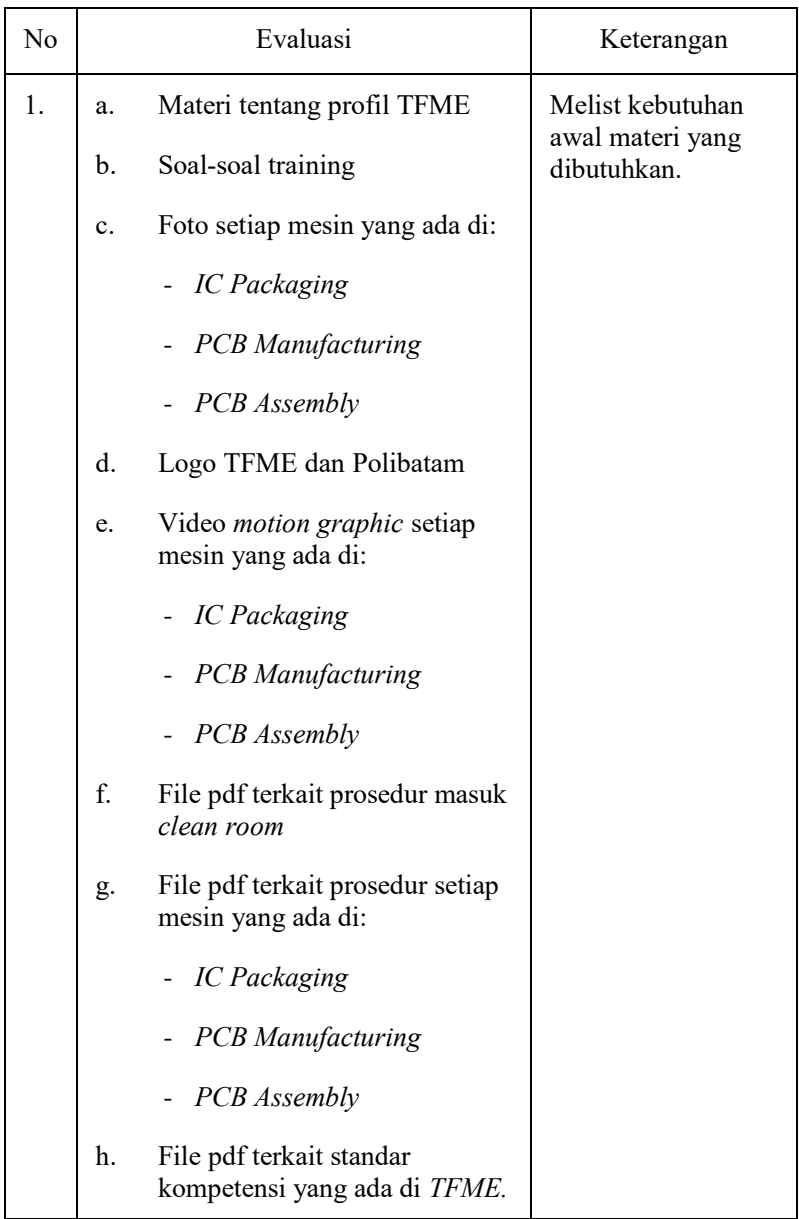




\begin{tabular}{|c|c|c|c|}
\hline 2. & c. & $\begin{array}{l}\text { Soal-soal kuis: } \\
\text { - IC Packaging } \\
\text { - PCB Manufacturing } \\
\text { - } \quad \text { PCB Assembly } \\
\text { File pdf dan video terkait } \\
\text { prosedur masuk clean room } \\
\text { File pdf terkait industrial } \\
\text { standard yang ada di TFME. }\end{array}$ & $\begin{array}{ll}\text { - } & \text { Untuk soal } \\
\text { training } \\
\text { diganti } \\
\text { menjadi soal } \\
\text { kuis dan } \\
\text { menambahkan } \\
3 \text { kategori } \\
\text { untuk kuis. } \\
\\
\text { Menambahkan } \\
\text { video terkait } \\
\text { prosedur } \\
\text { masuk ke } \\
\text { clean room. } \\
\\
\text { Untuk file pdf } \\
\text { standard } \\
\text { kompetensi } \\
\text { diganti } \\
\text { menjadi file } \\
\text { pdf industrial } \\
\text { standard. }\end{array}$ \\
\hline 3. & a. & $\begin{array}{l}\text { Materi tentang profil TFME } \\
\text { - Video motion graphic } \\
\text { tentang TFME } \\
\text { - Visi dan Misi } \\
\text { - Produk } \\
\text { - Fasilitas } \\
\text { - Kontak } \\
\text { Soal-soal kuis: } \\
\text { - IC Packaging } \\
\text { - PCB Manufacturing } \\
\text { - PCB Assembly } \\
\text { - K3 TFME } \\
\text { File pdf terkait general } \\
\text { specification yang ada di } \\
\text { TFME: } \\
\text { - Material: Datasheet dan } \\
\text { MSDS } \\
\text { - Drawing: POD, MTD, Spare } \\
\text { Part, dan Lead frame } \\
\text { /Substrate } \\
\text { - Industrial Standard: } \\
\text { JEDEC, AIAG, IPC, TFME } \\
\text { Spec, dan TFME Report. } \\
\text { - Clean Room: procedure dan } \\
\text { video } \\
\text { Materi terkait web instruction } \\
\text { File pdf terkait K3 TFME, } \\
\text { Foto produk yang ada di TFME. }\end{array}$ & $\begin{array}{l}\text { Menambahkan } \\
\text { video, visi \& } \\
\text { misi, produk, } \\
\text { fasilitas, dan } \\
\text { kontak ke } \\
\text { halaman } \\
\text { profil. } \\
\text { - } \\
\text { Menambahkan } \\
1 \text { kategori ke } \\
\text { soal kuis. } \\
\text { Mengganti } \\
\text { industrial } \\
\text { standard } \\
\text { menjadii } \\
\text { general } \\
\text { specification } \\
\text { dan } \\
\text { menambahkan } \\
4 \text { kategori ke } \\
\text { general } \\
\text { specification. } \\
\text { Menambahkan } \\
\text { materi terkait } \\
\text { web } \\
\text { instruction. } \\
\text { Menambahkan } \\
\text { file pdf terkait } \\
\text { K3 TFME, } \\
\text { failure } \\
\text { analysis dan } \\
\text { reliability. } \\
\text { Menambahkan } \\
\text { foto produk } \\
\text { TFME. }\end{array}$ \\
\hline
\end{tabular}

\section{b. Original contributions Design(perancangan)}

Dalam tahapan desain dilakukan perancangan storyboard, penentuan warna, dan jenis typeface yang akan digunakan.

1) Penentuan warna yang digunakan disesuaikan dengan ciri khas dari Polibatam dan TFME. Polibatam identik dengan warna biru sedangkan TFME identik dengan warna hitam. Template warna yang digunakan dalam desain interface produk dapat dilihat pada gambar 2 .

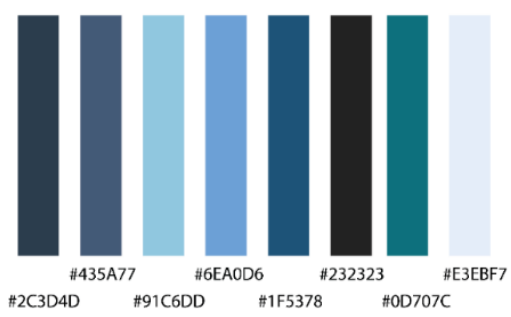

Gambar 2: Template warna

2) Typografi yang digunakan dalam desain ini adalah sans serif, jenis font yang digunakan adalah Bebas Neue dan Deansgate Condensed, dan typeface yang digunakan adalah regular. Bebas Neue merupakan jenis font dari keluarga sans serif yang terbaik dan cukup popular. Font Bebas Neue terlihat sangat tegas dan cocok tampil sempurna untuk setiap judul dan post [22]. Penggunaan jenis font ini dikarenakan font ini sederhana dan mudah untuk dibaca oleh pengguna. Jenis font dapat dilihat pada gambar 3 dan 4 .

\section{ABCDEFGHIJKLMNOPQRSTUVWXYZ ABCDEFGHIJKLMNOPQRSTUVWXYZ} $1234567890 . ., ; '$ " [??]+-*/=

Gambar 3: Font bebas neue

abcdefghijklmnopqrstuvwxyz ABCDEFGHIJKLMNOPQRSTUVWXYZ 1234567890::; ' " (!?) +-*/=

Gambar 4: Font deansgate condensed

3) Evaluasi yang dilakukan pada storyboard interface dapat dilihat pada tabel 4 .

TABLE 4

EVALUASI STORYBOARD






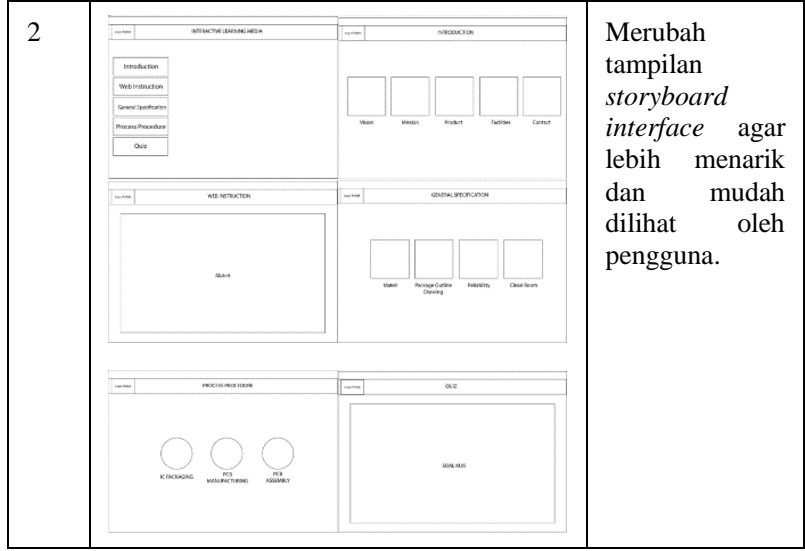

c. Development (pengembangan)

Dalam tahapan pengembangan dilakukan pengembangan desain dari storyboard interface pada tahapan desain sebelumnya. Pengembangan desain interface menggunakan software Adobe Illustrator dimana hasil akhir desain akan di eksport satu per satu bagian menjadi format .png. Evaluasi yang dilakukan pada tahapan pengembangan dapat dilihat pada tabel 5.

TABLE 4

EVALUASI STORYBOARD



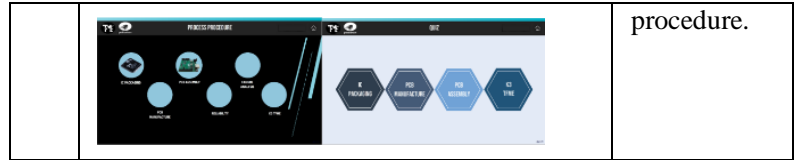

c. Implementation (implementasi)

Dalam tahapan implementasi dilakukan proses pembuatan produk TFME Interactive Learning Media sesuai dengan desain yang sudah dikembangkan pada tahapan development. Produk akan diimplementasikan ke dalam software Adobe Animate. Tahapan ini lebih lanjutnya akan dijelaskan pada bagian hasil dan pembahasan.

e. Evaluation (evaluasi)

Dalam tahapan evaluasi akan dilakukan proses evaluasi yang dilakukan setiap satu minggu sekali dan dilaksanakan secara terus-menerus hingga produk tersebut selesai dan sesuai dengan tujuan awal.

\subsection{Analisa}

Metode kuantitatif merupakan metode analisis yang akan dipakai untuk penelitian ini dimana instrumen pengumpulan data berupa kuesioner. Metode analisis user experience pada TFME Interactive Learning Media menggunakan metode penelitian user experience questionnaire (UEQ).

Tahapan penelitian dimulai dari studi literatur, implementasi produk, pengumpulan data dengan menyebarkan kuesioner, analisis dan pengolahan data menggunakan UEQ Data anaylisis tool, kemudian mengambil kesimpulan dari hasil analisa data tersebut. Gambar 5 merupakan gambar dari tahapan penelitian tersebut.

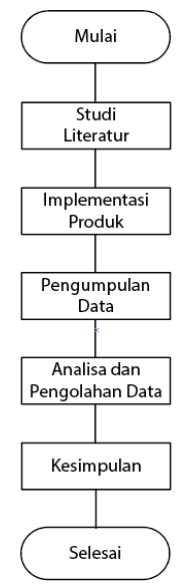

Gambar 5: Tahapan penelitian

a. Populasi, Sampel, dan Sampling

Populasi dari penelitian ini merupakan mahasiswa Politeknik Negeri Batam dari Program Studi

Teknik Elektronika dan Teknik Elektronika Manufaktur. Sampel dari penelitian ini adalah 70 
orang terdiri dari 35 orang mahasiswa Program Studi Teknik Elektronika dan 35 orang mahasiswa Program Studi Teknik Elektronika Manufaktur. Teknik sampling yang digunakan dalam penelitian ini adalah teknik simple random sampling, yaitu pengambilan sampel secara acak.

b. Teknik Pengumpulan Data

Teknik pengumpulan data yang digunakan dalam penelitian ini adalah dengan menggunakan kuesioner, dimana kuesioner UEQ merupakan intstrumen pengumpulan data. Kuesioner yang dibuat merupakan kuesioner online yang disebarkan melalui google form. Kuesioner yang digunakan juga tertutup, artinya kuesioner tersebut disampaikan sedemikian rupa sehingga responden hanya perlu menjawab di tempat yang sesuai. Di dalam kuesioner tersebut terdapat 26 buah pernyataan yang telah disertai dengan jawaban dengan rentang penilaian 1-7.

Produk akhir akan diujicobakan untuk memastikan bahwa media pembelajaran yang dihasilkan sesuai dengan yang direncanakan. Pengujian akan dilakukan oleh mahasiswa dengan memberikan kuesioner online kepada mahasiswa untuk mengetahui user experience pada TFME Interactive Learning Media sebagai media pembelajaran bagi mahasiswa. Kategori responden yang wajib mengisi kuesioner adalah mahasiswa Politeknik Negeri Batam dari Program Studi Teknik Elektronika dan Teknik Elektronika Manufaktur. Berikut adalah langkah-langkah pengujian yang dilakukan:

a. Responden menggunakan semua fitur yang ada di TFME Interactive Learning Media.

b. Responden mengisi kuesioner yang diberikan sesuai dengan kesan yang mereka rasakan ketika menggunakan TFME Interactive Learning Media.

Untuk mengetahui bagaimana kualitas user experience yang ada pada TFME Interactive Learning Media, maka media pembelajaran tersebut harus memenuhi beberapa aspek, yaitu kebaruan, kejelasan, ketepatan, efisiensi, daya tarik dan stimulasi. Jika aspek tersebut terpenuhi maka TFME Interactive Learning Media layak untuk digunakan sebagai media pembelajaran. Kerangka kuesioner UEQ yang dapat dilihat pada gambar 6.

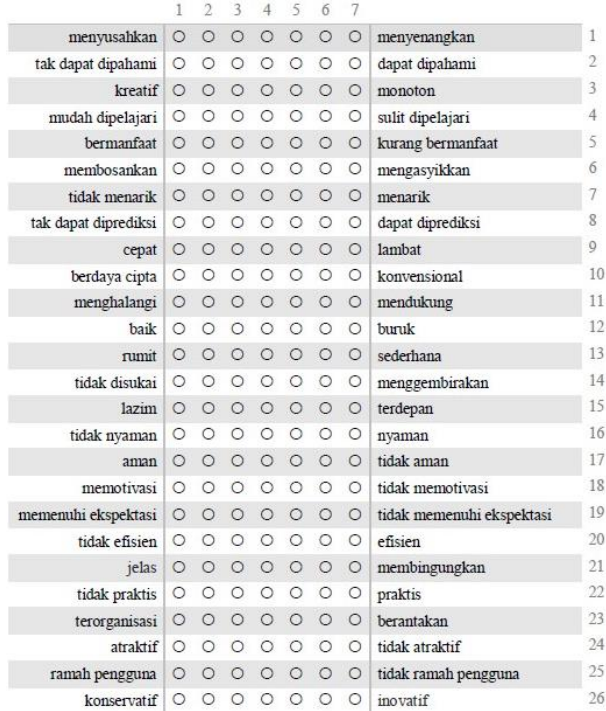

Gambar 6: Kerangka Kuesioner UEQ

\section{Teknik Analisis dan Pengolahan Data}

Analisis data yang digunakan dalam penelitian ini adalah statistik deskriptif. Statistik deskriptif adalah teknik statistik yang digunakan untuk menganalisis data dengan cara mendeskripsikan data yang telah terkumpul ke dalam tampilan grafik. Setelah data terkumpul, selanjutnya data akan diolah menggunakan tool khusus yaitu UEQ data analysis tool yang dapat diunduh dari website resmi UEQ. Hasil pengumpulan data kemudian dianalisa untuk mengetahui kualitas user experience dari TFME Interactive Learning Media. Berikut merupakan proses pengolahan data menggunakan UEQ data anaylisis tool:

a. Memasukkan data hasil kuesioner ke dalam tab "data" yang ada di UEQ data analysis tool.

b. Mentransformasi data, yaitu mengubah nilai 1 sampai dengan 7 menjadi -3 sampai dengan +3 . Dimana -3 merupakan nilai negatif terendah dan +3 merupakan nilai positif tertinggi.

c. Melakukan perhitungan rata-rata perorangan (mean per person).

d. Melakukan perhitungan rata-rata untuk setiap aspek UEQ.

e. Mendapatkan hasil UEQ yang dapat dilihat pada tab "benchmark". 


\section{Hasil dan Pembahasan}

\subsection{Hasil Analisa UEQ}

Tingkat user experience pada TFME Interactive Learning Media yang dilakukan menggunakan UEQ berupa kuesioner dengan 26 pertanyaan tentang produk diserahkan kepada 35 mahasiswa Program Studi Teknik Elektronika dan 35 mahasiswa Program Studi Teknik Elektronika Manufaktur. Setiap pertanyaan memiliki skala penilaian 1-7. Jawaban dari responden dimasukkan ke dalam tab "Data" yang mana nilai jawaban masih menunjukan skala penilaian 1 sampai dengan 7. Hasil jawaban kuesioner UEQ dapat dilihat pada gambar 7 .

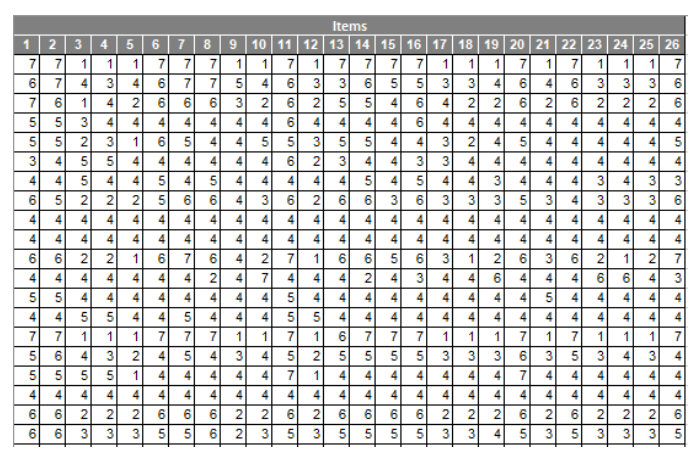

Gambar 7: Hasil Kuesioner UEQ

Dari setiap jawaban yang menunjukan skala penilaian, kemudian dilakukan tranformasi data pada $t a b$ " $D T$ " yang dapat dilihat pada gambar 8

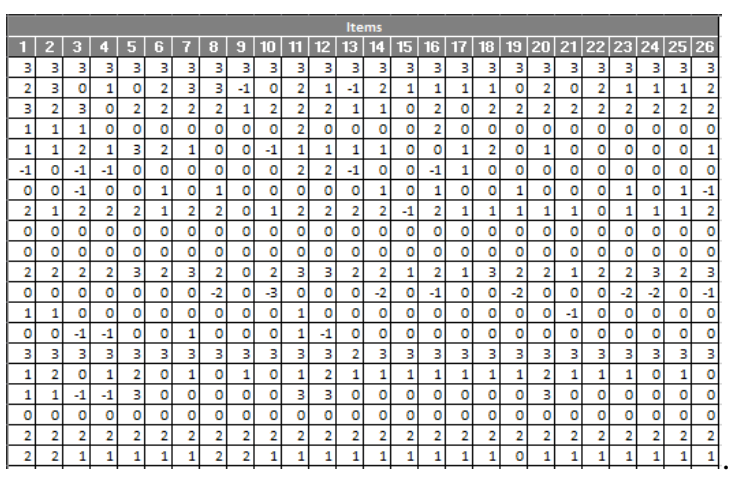

Gambar 8: Transformasi Data

Dari 70 jawaban responden untuk setiap pertanyaan, dilakukan perhitungan rata-rata per orangan pada $t a b$ " $D T$ " yang dapat dilihat pada gambar 9 .

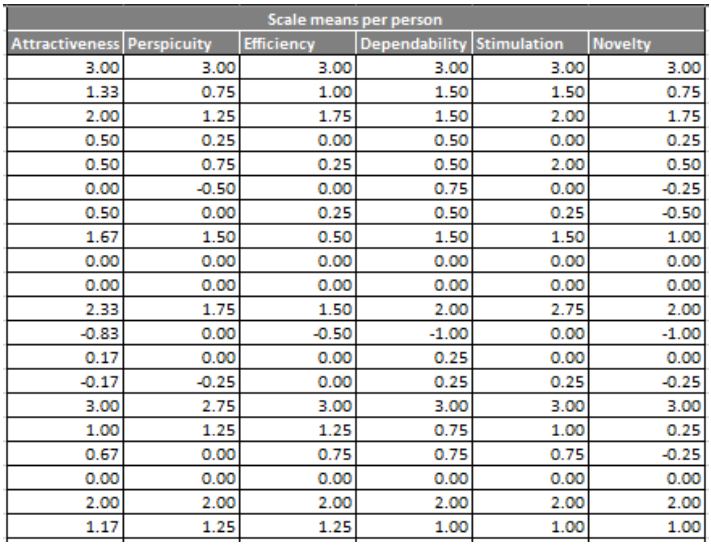

Gambar 9: Rata-rata perorangan

Kemudian dilakukan perhitungan rata-rata untuk setiap aspek dan pertanyaan UEQ pada tab "Result" yang dapat dilihat pada gambar 17 dan gambar 10 .

\begin{tabular}{|c|c|c|}
\hline \multicolumn{3}{|c|}{ UEQ Scales (Mean and Variance) } \\
\hline Attractiveness & 1.229 & 1.33 \\
\hline Perspicuity & ค1.089 & 1.36 \\
\hline Efficiency & ค 1.146 & 1.34 \\
\hline Dependability & ค 1.179 & 1.34 \\
\hline Stimulation & ลิ 1.204 & 1.38 \\
\hline Novelty & ค 1.032 & 1.38 \\
\hline
\end{tabular}

Gambar 10: Rata-rata setiap aspek

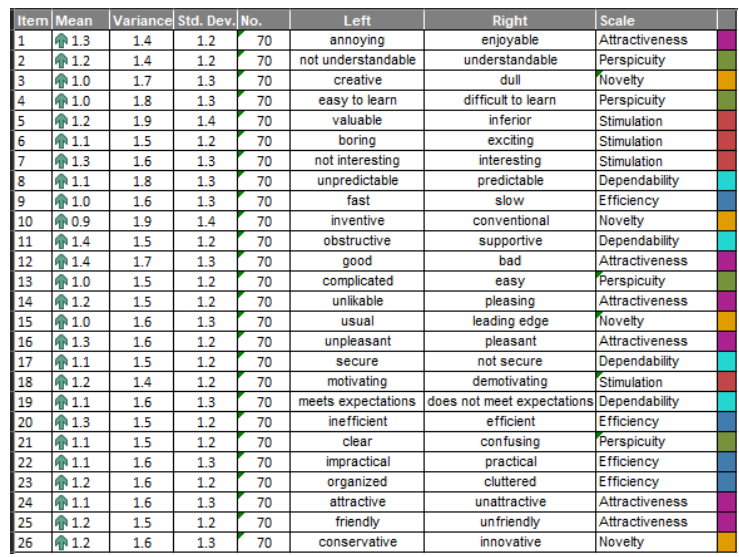

Gambar 11: Rata-rata setiap pertanyaan

Evaluasi normal merupakan nilai rata-rata kesan dari pengguna dengan rentang nilai antara $-0,8$ sampai dengan 0,8 . Evaluasi positif merupakan nilai rata-rata yang lebih besar dari 0,8. Evaluasi negatif merupakan nilai rata-rata yang lebih kecil dari $-0,8$ [15].

Berdasarkan rata-rata per aspek, dapat dilihat bahwa semua aspek UEQ yaitu attractiveness, perspicuity, efficiency, dependability, stimulation, dan novelty menghasilkan evaluasi positif yang ditunjukan dengan panah ke atas warna hijau. Sedangkan rata-rata setiap pertanyaan dapat dilihat bahwa semua 
pertanyaan menghasilkan evaluasi positif yang ditunjukan dengan panah ke atas warna hijau.

Hasil akhir analisis kuesioner UEQ dapat dilihat pada tab "benchmark" yang dapat dilihat pada gambar 12 .

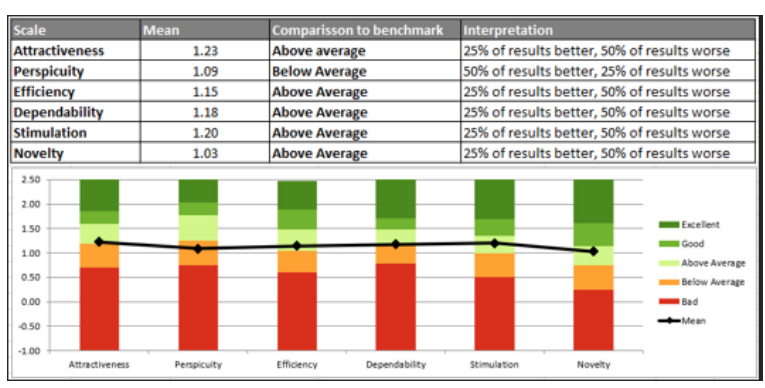

Gambar 12: Benchmark

Berdasarkan pada hasil dari tab "benchmark" dapat dilihat bahwa untuk aspek UEQ yaitu attractiveness (1.23), efficiency (1.15), dependability (1.18), stimulation (1.20), dan novelty (1.03) berada di atas rata-rata. Sedangkan aspek perspicuity (1.09) berada di bawah rata-rata.

\section{Kesimpulan}

TFME Interactive Learning Media dapat menjadi media pembelajaran untuk mahasiswa dari Program Studi Teknik Elektronika dan Teknik Elektronika Manufaktur. Selain itu, kualitas pengalaman pengguna terhadap TFME Interactive Learning Media menggunakan user experience questionnaire dapat diketahui bahwa media pembelajaran tersebut memiliki 6 aspek UEQ yang mendapatkan nilai rata-rata $>0.8$ yaitu aspek daya tarik (1.23), kejelasan (1.09), efisiensi (1.15), ketepatan (1.18), stimulasi (1.20) dan kebaruan (1.03).

\section{Daftar Pustaka}

[1] T. Setiawati, "Peranan Teknologi dalam Dunia Pendidikan," 2018. [Online]. Available: https://www.kompasiana.com/tutinamaku/5bcaf0 2643322f2c44578c72/peranan-teknologi-dalamdunia-pendidikan?page=all. [Accessed 27 Oktober 2020].

[2] Setyawan, I.A, "Pengertian Contoh dan Aplikasi Pembuat Multimedia Pembelajaran Interaktif," 2020. [Online]. Available: https://gurudigital.id/pengertian-contoh-dan-soft ware-pembuat-media-pembelajaran-interaktif/. [Accessed 27 Oktober 2020].

[3] Polibatam, "Teaching Factory Polibatam," 2018. [Online]. Available: https://www.polibatam.ac.id/teaching-factory-pol ibatam/. [Accessed 03 November 2020].

[4] Assad, N.S, Interviewee, Interview terkait TFME Interactive Learning Media dan TFME. [Interview]. 9 November 2020.

[5] A. L. T. Adinegoro, R. I. Rokhmawati and H. M. Az-Zahra, "Analisis Pengalaman Pengguna pada Website E-Commerce dengan Menggunakan Usability Testing dan User Experience Questionnaire(UEQ) (Studi pada Lazada.co.id, Blibli.com, dan JD.id)," Jurnal Pengembangan Teknologi Informasi dan Ilmu Komputer, vol. 2, no. 11, pp. 5862-5870, 2018.

[6] Susilo. E, "Pengertian User Experience(UX) dan Mengapa User Experience itu Penting?," 2019. [Online]. Available: https://www.edisusilo.com/pengertian-user-exper ience/. [Accessed 27 Oktober 2020].

[7] Rauschenberger, M., Schrepp, M., Pérez Cota, M., Olschner, S. and Thomaschewski, J., 2013. Efficient measurement of the user experience of interactive products. How to use the user experience questionnaire (UEQ). Example: Spanish language version.

[8] Schrepp, M., 2015. User experience questionnaire handbook. All you need to know to apply the UEQ successfully in your project.

[9] L. A. Abdillah, "Analisis Aplikasi Mobile Transportasi Online Menggunakan User Experience Questionnaire pada Era Milenial dan Z," Jurnal Sistem Informasi Bisnis, 2019.

[10] A. Sularsa, E. Nugroho and A. S. Prihatmanto, "Evaluasi User Experience Produk iDigital Museum dengan Menggunakan UEQ," Jurnal Teknologi Informasi Vol.2, No.2, 2015.

[11] Audi, M., Rokhmawati, R.I. and Az-Zahra, H.M., 2018. Analisis Aspek Usability dan User Experience Website dan Aplikasi Mobile Radio Streaming (Studi Pada Website dan Aplikasi Mobile Radio Prambors). Jurnal Pengembangan Teknologi Informasi dan Ilmu Komputer e-ISSN, 2548, p.964X.

[12] Pratomo, A. and Irawan, A., 2015. Pengembangan media pembelajaran interaktif berbasis web menggunakan metode Hannafin dan Peck. Positif, 1(1), p.159673.

[13] Puji, K.M., Gulo, F. and Ibrahim, A.R., 2014. Pengembangan multimedia interaktif untuk pembelajaran bentuk molekul di SMA. Jurnal Penelitian Pendidikan Kimia: Kajian Hasil Penelitian Pendidikan Kimia, 1(1), pp.59-65.

[14] Hartawan, M.S., 2019, April. Analisis User Experience Untuk User Interface Pada Website 
Fortis. Id. In ESIT (Vol. 14, No. 1, pp. 55-61).

[15]Krisnayani, P., Arthana, I.K.R., Darmawiguna, I.G.M. and Kom, S., 2016. Analisa Usability Pada Website UNDIKSHA Dengan Menggunakan Metode Heuristic Evaluation. KARMAPATI (Kumpulan Artikel Mahasiswa Pendidikan Teknik Informatika), 5(2), pp.158-167.

[16] Isabella, D.I.S., Martono, K.T. and Eridani, D., 2020. User experience pada Implementasi Virtual Reality sebagai Media Pembelajaran Anak Pengidap Autisme. Jurnal Komputer Terapan, 6(1), pp.1-12.

[17] Kharis, P.I.S. and Winarno, W.W., 2019. Evaluasi User Experience pada Sistem Informasi Pasar Kerja Menggunakan User Experience Questionnare (UEQ).

[18]Henim, S.R. and Sari, R.P., 2020. Evaluasi User Experience Sistem Informasi Akademik Mahasiswa pada Perguruan Tinggi Menggunakan User Experience Questionnaire. Jurnal Komputer Terapan, 6(1), pp.69-78.

[19]Sari, B.K., 2017. Desain Pembelajaran Model ADDIE dan Implementasinya dengan Teknik Jigsaw.

[20]Arieska, P.K. and Herdiani, N., 2018. Pemilihan Teknik Sampling Berdasarkan Perhitungan Efisiensi Relatif. Jurnal Statistika Universitas Muhammadiyah Semarang, 6(2).

[21]Dewi, N.R. and Sudhana, H., 2013. Hubungan antara komunikasi interpersonal pasutri dengan keharmonisan dalam pernikahan. Jurnal Psikologi Udayana, 1(1), pp.22-31.

[22]C. "30+ Font Sans Serif Terbaik Untuk Heading Website," 2020. [Online]. Available: https://www.centerklik.com/font-sans-serif-terba ik-heading-website/. [Accessed 7 Desember 2020]. 